World Maritime University

The Maritime Commons: Digital Repository of the World Maritime University

Proceedings of the International Maritime

Lecturers' Association (IMLA) 2021

Conference Proceedings

2021

\title{
Utilization of non-verbal language in engine room training
}

\author{
Emi Yutaka \\ Japan Agency of Maritime Education and Training for Seafarers \\ Muramatsu Nagisa \\ Japan Agency of Maritime Education and Training for Seafarers
}

Follow this and additional works at: https://commons.wmu.se/imla2021

Part of the Education Commons

\section{Recommended Citation}

Yutaka, E. \& Nagisa, M. (2021). Utilization of non-verbal language in engine room training. In Pazaver, A., Manuel, M. E., Bolmsten, J., Kitada, M., Bartuseviciene, I. (Eds.), Proceedings of the International Maritime Lecturers' Association. Seas of transition: setting a course for the future (pp. 145-148). World Maritime University. http://dx.doi.org/10.21677/imla2021.15

This Paper is brought to you courtesy of Maritime Commons. Open Access items may be downloaded for noncommercial, fair use academic purposes. No items may be hosted on another server or web site without express written permission from the World Maritime University. For more information, please contact library@wmu.se. 


\title{
Utilization of non-verbal language in engine room training
}

\author{
Emi Yutaka \\ Professor, Chief Engineer, Japan Agency of Maritime Education and Training for Seafarers, \\ Yokohama, Japan, emi-y5t4@jmets.ac.jp
}

\section{Muramatsu Nagisa}

Onboard Instructor, Second Engineer, Japan Agency of Maritime Education and Training for Seafarers, Yokohama, Japan, muramatsu-n7p1@jmets.ac.jp

\begin{abstract}
The Engine control room in a vessel is covered with a soundproof wall. Therefore, crews can not communicate with each other with normal voices. Therefore, crews in the engine room communicated with colleagues by hand signals instead of loud voices in the noisy space when there was no control room yet in a vessel. An example of a hand signal that Japanese crews used to use in the past was putting your right hand into your left armpit, which means "measure". One of the advantages of hand signals is that they are a useful communication tool in such a noisy environment. In addition, as another advantage, if there are internationally common maritime hand signals, it would be a useful communication tool among multicultural and multilingual crews on board. This paper focuses on engineer instructors on training ships. They use megaphones when they need to explain something or give orders to cadets in noisy engine rooms. Thus, taking into account the past hand signals used by Japanese crews and the diversity of meaning of gestures in different countries, we study the potential for utilizing hand signals during training in noisy engine rooms.
\end{abstract}

Keywords: hand sign in engine room, multicultural crews' communication, communication in engine room.

\section{Introduction}

It is sometimes difficult for non-native English speakers to communicate in a multicultural environment. One of the reasons for such difficulties is that the syllabic accent and/or pronunciation of English is often affected by their own mother tongues. In addition, especially in the engine room, communication is also hard for crews because of noisy circumstances. Before engine control rooms came into wide use, Japanese engine crews used to communicate with each other by utilizing "hand signals", which are made with one hand and have a common meaning, in the engine room. One example is "measure", which is expressed by putting your right hand into your left armpit. This is the same motion as measuring your body temperature with a clinical thermometer. In this paper, "hand signal" is distinguished from "sign language" and "gesture". Basically, sign language is composed of hand gestures, body language and facial expressions to build up the intended meaning. Moreover, sign language is mainly used by people who have experienced hearing loss. According to the Oxford Advanced Learner's Dictionary of current English, gesture means a movement that you make with your hands, your head, or your face to show a particular meaning. However, in this paper, "hand signal" is defined as a communication tool by use of only one hand. We would like to introduce examples of current use of hand signals and study future possibilities for utilization of hand signals. 


\section{Non-verbal communication with partners on a vessel}

While crew in the deck department utilize gestures with interphone, walkie talkie and whistling during communication between bridge and bow, engine crew tend rarely to use non-verbal communication in the engine room. An example of a rare case of non-verbal communication in the Training Ship Kaiwo Maru of JMETS (Japan agency of Maritime Education and Training for Seafarers) is manual operation at the engine side. Engine crews utilize gestures between partners: one is the main engine operator and the other is the clutch operator. A main engine operator sends a message to the clutch operator by showing his/her hand: spreading all his/her fingers and showing his/her palm. If the main engine operator bends all his/her fingers and shows his/her hand, the meaning is the request to disengage the clutch of the reduction gear. Taking the above two cases into account, non-verbal communication is an effective way of communicating the sender's intention to another who is especially far away from the sender.

\section{Past communication in engine room}

At present, communication relating to operational work in the engine room is mostly conducted between the engine control room and the engine room by interphone or walkie-talkie. Unlike the current situation, before not only the engine control room but also walkie-talkie appeared, Japanese engine crew utilized hand signals when communicating with each other in the noisy engine room. One of the advantages of communication by hand signals is to be able to understand mutual intentions without relying on auditory perception. Thanks to the control room and walkie-talkie now, engine crews can exchange their information without loud voices. As a result, hand signals are no longer important skills for engine crew.

\section{Possible miscommunication among cross cultural environments}

Adequate communication contributes to preventing human error; however, nationalities of seafarers who are onboard seagoing vessels are diversified. Therefore, Maritime English as an official language on a vessel is one of the most important skills for seafarers, especially those whose mother tongues are not English. Key factors of English skills are vocabulary, grammar, listening, and speaking. Thus as far as cross cultural circumstances are concerned, pronunciation could be an important factor for smooth communication. This is because different pronunciations can result in different recognition by others. For instance, if you pronounce the alphabet from A to Z, you might pronounce it differently from others depending upon your mother tongue. Such diversity sometimes leads to misunderstanding others' intentions.

\section{Similarity between hand signal communication in the engine room and communication in multicultural environments}

Hand signal communication in the engine room seems to prevent misunderstandings due to utilizing visual information rather than auditory information. Then one of the features of difficulties for maritime English communication in multicultural environments is possibly cultural diversity of pronunciation. In order to deal with the diversity of pronunciation, utilization of visual information as an assistant tool for communication is helpful.

\section{Model of utilization of hand signals: adjusting the pressure for main engine lubricating oil}

A typical example of possible misoperation caused by miscommunication is valve handling while adjusting fluid pressure. When a duty engineer and a duty rating try to line up the main engine lubricating oil (hereafter, lub. oil) system, the duty engineer checks the lub. oil line pressure and gives instructions on how to operate the return valve to the rating after starting the main engine lub. oil pump. The role of the engineer is checking the main engine inlet 
pressure for lub. oil and giving instructions to the rating about how and how much to operate the return valve in order to adjust the inlet pressure on one hand, and the role of rating is turning in the direction to open or close the return valve depending upon the engineer's instruction on the other. (In this operation, the return valve is fully opened when starting the pump and will be closed to increase the pressure.) Causes of errors that might occur in this case are as follows:

- rating paid attention to the valve itself but not the pressure;

- rating operated the valve the wrong way;

- engineer gave the wrong order;

- engineer and/or rating confused which operation should have been done because of alternative repetition of operation; and

- engineer used the word "increase" or "decrease" because his/her intention is pressure increase or decrease instead of "open" or "close" to rating.

Taking the above causes into account, especially in the last case, it is easier to avoid the error if hand signals are used. Thus, while adjusting the lub. oil line pressure, both engineer and rating communicate through utilizing hand signals as Table 1 shows.

Table 1.

Meanings of hand signals

\begin{tabular}{|l|l|}
\hline Stop & Bending all fingers and hold on your hand \\
\hline Open & $\begin{array}{l}\text { Open your right hand as you show your palm to your colleague and then } \\
\text { turn it counter-clockwise (turn to thumb side) twice. }\end{array}$ \\
\hline Close & $\begin{array}{l}\text { Open your right hand as you show your palm to your colleague and then } \\
\text { turn it clockwise (turn to opposite side of thumb) twice. }\end{array}$ \\
\hline Speedy & $\begin{array}{l}\text { Stretch your forefinger (or index finger) like pointing out at the sky and then } \\
\text { turn your forefinger as you draw a horizontal arc with your fingertip of } \\
\text { forefinger. }\end{array}$ \\
\hline Slowly & $\begin{array}{l}\text { Stretch your little finger (or fifth finger) like stretching your little finger to } \\
\text { the sky and turn it. }\end{array}$ \\
\hline
\end{tabular}

The reason why the hand signals for "open" and "close" are defined as in the above table is that they correspond to the direction, clockwise or counter-clockwise, in which you need to turn a valve if you want to open or close it. You can open a valve when you put your right hand on the top of the spindle of the valve and turn it counter-clockwise no matter which direction the valve is installed vertically or even upside down. This instruction is often used for cadets of initial stage or familiarization level. The above "Speedy" is also possible to use as "More" and "Slowly" as "A little bit"

The detailed operation including the hand signals shown in the above table after starting lub oil pump is as follows:

(1)Sending the message "Slowly" and then "Close" by hand signals (The rating closes the return valve gradually and keeps turning the valve as long as the engineer is moving their hand);

(2)Changing the message to "Speedy" until the pressure rises when the engineer confirms no deficiencies in the system. (The rating changes the speed of closing valve to relatively speedy.);

(3)Showing "Slowly" again, when confirming the pressure is rising;

(4)Showing "Stop" when the pressure reaches the target level;

(5)Showing "Slowly" and then "Open" when the actual pressure is beyond the target level on one hand, and "Slowly" and then "Close" when the actual pressure is still below the target level on the other. Maintain the operation until the actual pressure reaches the target level.; and 
(6)Showing "Stop" when the pressure adjustment is complete.

\section{Hand sign as a support tool for communication in the engine room}

Engineering crew are exposed not only to noise but also to high temperature or vibration from machinery. Therefore, communication in the engine room is always carried out while paying attention to such a hazardous environment. In particular, the disadvantage of auditory perception has considerably affected communication in the engine room. In addition to this shortcoming, English communication in a cross-cultural environment sometimes leads to difficulties for crew in understanding each others' intentions. Communication under a combined hazardous and noisy environment with multicultural circumstances should be settled in. To compensate for this difficult condition, the utilization of hand signals will be one solution to improve communication in multicultural circumstances in the engine room. As mentioned in the introduction, the definition of "hand signal" in this paper is distinguished from both "gesture" and "sign language" in the viewpoint of "visual information using only one hand". For further study, we would like to analyse possible incidents caused by miscommunication, and develop systematic hand signals for better multicultural communication.

\section{References}

Hornby, A.S., Oxford advanced learner's dictionary of current English, $9^{\text {th }}$ edition, Oxford university press. p.655. 